\title{
Meta
}

Journal des traducteurs

Translators' Journal

\section{The Translation of Advertisements: Registeral and Schematic Constraints}

\section{Abdullah Shakir}

Volume 40, numéro 1, mars 1995

URI : https://id.erudit.org/iderudit/004123ar

DOI : https://doi.org/10.7202/004123ar

Aller au sommaire du numéro

Éditeur(s)

Les Presses de l'Université de Montréal

ISSN

0026-0452 (imprimé)

1492-1421 (numérique)

Découvrir la revue

Citer cet article

Shakir, A. (1995). The Translation of Advertisements: Registeral and Schematic Constraints. Meta, 40(1), 62-72. https://doi.org/10.7202/004123ar
Résumé de l'article

L'auteur presente les résultats d'une recherche menée auprès de ses étudiants pour déterminer à quel point ils sont conscients de certains types de connaissances. À partir d'exercices de traduction publicitaire, il évalue le degré de connaissance des étudiants concernant les contraintes de registre et les connaissances schématiques sous-tendues par I'arrière-plan culturel du texte de départ. 


\title{
THE TRANSLATION OF ADVERTISEMENTS: REGISTERAL AND SCHEMATIC CONSTRAINTS
}

\author{
ABDULLAH SHAKIR \\ Yarmouk liniversirs. Irbid. Jordan
}

\begin{abstract}
Résumé
l'auteur présente les résulfuss d'une recherche menée auprès de sés éfudiants pour déterminer à quel point ils sont conscients de certains wpes de comnaissances à partir de exercices de traduction publicitaire, il sualue le degre de connassance des étudiants concernam les contraintes de registre en le's commaissance's schematiquess some-sendues par larrière-plan culuerel du teverde' depart.
\end{abstract}

\section{INTRODUCTION}

Discourse analysts, ('.g. Hatim and Mason (1990), Leech (1972), Crystal and Davy (1979). Pinchuck (1977). Dolitsky (1984), have studied sales advertisements from different perspectives. Hatim and Mason (1990) classify advertisements as instructional texts that aim at provoking action or reaction via persuading and inviting. They discuss certain textual features that translators need to take into account when they translate an advertisement from one language into another. Leech (1972) and Crystal and Davy (1979) investigated the syntactic, semantic, and discoursal leatures that distinguish advertisements, as a text type in its own right. from other text types. Leech speaks of English sales advertisements as a type of disjunctive discourse characterized by simplicity of structure, shortness of sentences, unconventionality of style, and implicitness of cohesive connectivity. Pinchuck (1977) focuses on the surface features in advertisements that are likely to cause difficulties to the translator. He argues that sales advertisements aim to impress the reader by their individualistic language. Therefore. he maintains. the aim is not to achieve a oneto-one correspondence, $"$. ... but to absorb the mood of the ullerance and to attempt to recreate that mood in the TL." (p. 170)).

The study of the structure and rhetoric of advertisements for translation purposes aims to find in the first place in what ways and to what extent a translated version of an advertisement can create effects on the TL audience equivalent to those created by the source language (SL) text on the SL atudience. The notion of translation equivalence (TE) has been approached from different perspectives. Catford (196.5) discusses equivalence in terms of formal or grammatical correspondence wherein the textual material in one language is rendered in equivalent textual forms in another language. Jakobson (1959), on the other hand. focuses on the message rather than the form. Nida (1977) and de Ward and Nida (1986) also call for dynamic/functional equivalence, as it is the message that stays longer in the memory and thus figures as a frame of reference in the process of translating. In a recent study of (TE). Lotfipour-Saidi (1990) explains that translation equivalence is an outcome of the interaction among discoursal features. viz... structure. texture, vocabulary, language varieties, and cognitive effect. According to him the role of each of the above features will vary in each text type in response to contextual factors, thus giving more prominent roles to some of the above features while subordinating those of others. 
The notion of maintaining equivalent effect in advertisements translated from English into Arabic, or vice versa, has not received due attention from discourse analysts and translators or translator trainers. Nor have the factors that can either promote or impede establishing equivalence, whether such factors are language bound or cognitively or culturally motivated. In this context, a number of textual and contextual dimensions relevant to the study of translating advertisements from English into Arabic, or vice versa, need to be explored. Of particular interest here are the ways in which the Iranslator fails, to convey the intended message; the ways in which an advertisement may prove opaque to the translator; the linguistic givens in an advertisement that may enhance or impede translating: and the situative and cultural dimensions associated with the advertisement in question.

Thus, rendering into the target language a message conveyed via text equivalent in content and function to that conveyed in the source language seems to derive not only from linguistic knowledge. but also from schematic or encyclopedic knowledge, especially when the text/advertisement is culturally based. In the process of translating, schematic knowledge is usually triggered off by some key lexical items in the advertisement.

This type of knowledge is internalized by the native speaker and represents part of his knowledge of the world. In ambiguous and culturally-based advertisements, ambiguity is often brought about by certain lexical items that trigger off more than one schema or script (Raskin 1986: 1985). Often such schemata hold oppositeness relationship, hence the opaqueness of such texts. By oppositeness it is meant here that, one schema is viewed as relevant to the translator's experiences and knowledge of the world, while the other irrelevant and incongruous to his/ her knowledge. How the translator renders such a type of advertisement seems to depend to a certain extent on which schemata he deems relevant and congruous with his knowledge of the world. And in this context, schematic knowledge seems to contribute in three ways toward promoting equivalence in translation. Firstly, it employs cultural background in a way that may help in shaping the translation of both the content of the text and the intention of the writer/speaker in a manner the translator deems to be most appropriate. Secondly, it activates inferential elaboration of content and purpose of the text, thus providing basis for filling gaps. Thirdly, schemata provide correspondence between already established knowledge and the givens in a text, which may help the translator check his interpretation of the text.

\section{THE PRESENT STUDY}

\section{Subjects}

Twenty school teachers pursuing a B.A. degree in English at Irbid Higher College for Certification of Teachers, and six M.A. (Translation) students were asked to translate into Arabic five sales English advertisements. By the time the experiment was conducted, the school teachers had done two general translation courses.

\section{Materials}

The study is based on five English sales advertisements. Four of them are taken from New's Week, while the fifth from Brown and Yule (1985). The topics of the first four advertisements are familiar to the student translators: Rothmans, Dunhill. Marlboro, and Johnson's Baby Powder. The fifth advertisement was given to the students as a contextless text which has a culture-specific content.

\section{Purposes of the Study}

The study aims to answer the following questions:

1. What surface features need to be available in a translated version of an SL advertisement in order for the translation to have impact on and appeal to the target language audience? 
2. What criteria can be adopted for checking the appropriateness of the translation rendered of an SL, advertisement?

3. What cognitive strategies do student translators (and translators in general) use in the process of handling culturally-opaque advertisements?

In addition, the study aims to suggest a methodology that translator trainers may find helpful in evaluating translator trainees' translation of texts of register-specific nature.

\section{Methods of Collecting Data}

The advertisements were translated into Arabic in a 90-minute translation session. The students were allowed to use dictionaries. A random sample comprising the translations provided by fifteen students of the first four advertisements was given to eightyeight Yarmouk University students comprising three sections the present researcher taught during the first semester of 1992. The students in each section were asked to split into groups of five or six students each and to comment on the translations in terms of the style in which they were written. They were told that the texts in hand were translations of English advertisements. Their comments were then studied, analyzed, and categorized.

The rationale behind the above step was to elicit from a group of native speakers of Arabic a set of guidelines for evaluation based on native speakers experience. intuitive knowledge, and operational definition of register. This step, combined with an extensive analysis of a sample of Arabic sales advertisements, was meant to provide sufficient authority for the statements made in this study about different aspects related to the translations provided hy the students.

In order to validate the evaluation criteria adopted in this study, a sample of fiftyseven Arabic sales advertisements published in three Jordanian newspapers were analyzed for linguistic and stylistic features. Recurrent lexical, syntactic, and semantic features were recorded and categorized (see below). The method adopted for categorizing the features recorded in the analysis is insighted by the data collected in the previous phase (i.e. students' comments) and the analysis of the sample of the Arabic sales advertisements. The features are categorized in lerms of bipolar oppositions: formal/informal. simple/complex. Though the two sets of opposition might suggest two independent divisions, they, in fact, intersect at various levels.

\section{DISCUSSION}

\section{Analysis of the Arabic Sales Advertisements:}

The sample of Arabic sales advertisements was analyzed to obtain data on:

a. frequency of compound sentences and the types of coordinators used:

b. frequency of complex sentences and the type of subordinators used:

c. frequency and types of cohesive connectives used:

d. frequency of formal and informal lexical items used.

The 57 advertisements consisted of 243 sentences. Of these only 22 were compound sentences conjoined by coordinators such as $w^{\prime} a$ (and), wa-läkin (but). Complex sentences were not more than 28 , and the subordinators which recurred frequently were $l i$ (in order to), li-kay (in order to), idki (if), hastät verh (so as to). Most of these subordinators occurred in introductory clauses; as in (1) helow: 
(1) 'ida kuniatqad qarrarsa man'id haflat if have+you fixed date party zafafik fa-t-tasil mar abu cali wedding+your hen-telephone with Abu Alityou $\begin{array}{ll}\text { li-t-taswir } & \text { il-fanni } \\ \text { for-the-photography } & \text { the-technical }\end{array}$

"If you have fixed the date of your wedding party, call Abu Ali for technical photography"

The analysis has shown that long sentences of complex structure tend to be rare in Arabic sales advertisements. The reason could be that writers of advertisements prefer to provide the message in short, easily processible chunks. The analysis has also shown that the overwhelming majority of the texts are written in disjunctive language where appositional and paratactic sentences form a dominant textual feature. Non-linked coordination seems to be preferred to linked coordination so that parataxis emerges as a linguistic phenomenon common enough in Arabic sales advertising to be considered a real alternative to linked coordination or subordination. Ellipsis, in addition to appositional relationship, emerges as the second most preferred cohesive relationship. It indicates the cooperative attitude on the part of the receiver that the writer seems to base his/her text upon. Further, it indicates the receiver's tolerance of the exaggerated relation alleged to hold between the advertised product and the attributes assigned to it. At the cognitive level, it aims to reduce memory load by providing the intended message in small morsels which are easier to process. To illustrate, observe the structure of (2) and (3):

(2) Klänà al-jüda l-caliya

Clara the quality the high

at-farmu l-mumavyaz

the taste the distinguished

"Clara: the highest quality the distinguished taste"

(3) aymanli l-maräyä

Ayman for the mirrors

'al-manáxi l-makfüla

the mirrors the guaranteed

la tutalatsar bil-mä'i au'il-buxär

not affected by the water or the steam

"Ayman for mirrors: The guaranteed mirrors. The mirrors that do not steam up"

A close look at (2) above reveals that some information is withheld on the assumption that the reader can retain it from the co-text. And here we see that linguistic and nonlinguistic factors interact in complete harmony which derives from the unwritten contract of cooperation between the writer and the reader. The writer assumes tolerance on the part of the reader of the alleged uniqueness of the product being advertised. Hence, the recurrence of the definite article al (the) with aljüda (-'aliva (the quality the high) and atta'mu /-mumayvaz (the taste the distinguished). The cooperative relationship is further manifested in withholding from the reader a piece of information the writer assumes he/she (the reader) can retrieve from the immediate context. A further interpretation of why such a clause like ...is a kind of hiscuit that represents is ellipted could be that had that piece been explicitly expressed, the advertisement would have been seen as a formal academic text taking on a definition function. Text (3) also manifests preference for implicitness of connectivity over explicitness. Two relationships hold together the component sentences of the text. The first is an appositional relationship that brings together ayman li l-maräyä (Ayman for mirrors) and al-maräyă l-makfüla (the guaranteed mirrors) 
by referential equivalence. The third sentence là tata'attaru bi l-mā'i 'aw'il-buxār (is water and steam proof) links with the previous one by means of an implicit relationship of cause-effect.

Except for a very limited number of technical vocabulary items, such as at-laxmin il-caqari (assessment of real estate), dubläj wa muntäj (dubbing and montage), diràsat iljadwä (feasibility study), tawäss il-murabah (soil properties), ctc. the lexical choices in the sample of advertisements derive from common core Arabic vocabulary addressed to readers of different educational standings.

\section{The Students' Comments}

As mentioned in the section above. a sample of the translations was given to 88 students to comment on them. Sixty comments were received. 33 of them were critical of the translations. These comments were categorized as follows:

1. the advertisements neither satisfy the intended clients nor please the reader (3.3.6\%);

2. awkward style (2.3.8\%):

3. language too formal $(18.2 \%)$ :

4. sentences too long (12.5\%):

5. style similar to scientific and academic discourse $(11.9 \%)$

These comments, though extremely general, are highly suggestive. The order in which the comments appear reveals that what first struck the readers was the unsatisfying and unpleasing style a large number of the advertisements were written in. This comment, scoring the highest percentage, can be taken as a super-ordinate and, therefore, the most general impressionistic judgement of the translations. The rest of the comments seem to function as substantiators of the superordinate one. They specify why the translations are neither satisfying nor pleasing. Thus, one can conclude that for a translation of an advertisement to be communicatively acceptable and rhetorically effective, it has to meet certain criteria. Such criteria can be derived from the comments (2-5) as indicators of stylistic qualities missing in the translations provided.

A closer look at the students comments reveals that two crucial characteristics in the translations are missing. vis... impart and appeal (Nida 1990). By impact, we mean the effect linguistic choices and rhetorical devices employed in the text can have upon the intended reader. Appeal here refers to the attitude or response of the receiver as he/she takes in the message via the textual medium. The two characteristics should be viewed in their interactive function: a text appeals to the reader when it is conveyed in a way that meets the audience's anticipations of how such a text of such a function usually unfolds. The way textual components are arranged, and the way the content is struclured seem to play a key role in creating a text/advertisement that appeals to the intended audience.

\section{Analysis of the Students' Translations}

The discussion in this section will focus on two major areas relevant to the structure and texture of the texts under consideration. These areas are:

1. The surface structural features of the translations and the appropriateness of such features to the registeral characteristics of Arabic sales advertisements. The discussion is informed by the discussion in the previous sections.

2. The effect of such surface manifestations on the text typological focus of the texts / advertisements. 


\section{Surface Structural Features}

The following aspects are considered:

Sentence Structure

The analysis of the Arabic sales advertisements has shown that a characteristic feature of the 57 Arabic advertisements is shortness, simplicity, and disjunctiveness of their component sentences. Hence subordination and coordination are rarely used. A look at the students translations shows that subordination is a salient feature in about $54 \%$ of them. Subordinators, such as al-latil'al-ladi (which/that). hay/u (where/as). litverb (in order (o), li anna( $h u$ ) (because it is) li-kawnihi (as/because it is), hi-l-'idäfati 'ilä 'annahu (besides), idāfatan 'ilā (in addition), etc., are recurrently used to connect sentences. Observe, for instance, the texts in (4) and (5) below:

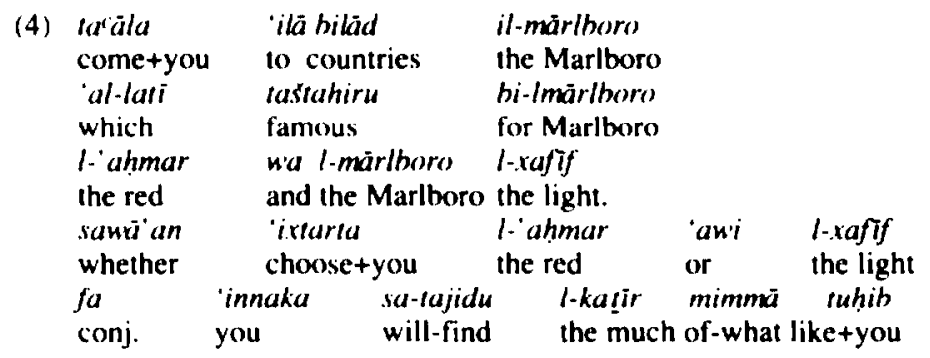

"Come to the Marlboro country which is famous for its red Marlboro and light Marlboro. Whether you choose the red or the light. you'll get a lot of what you like."

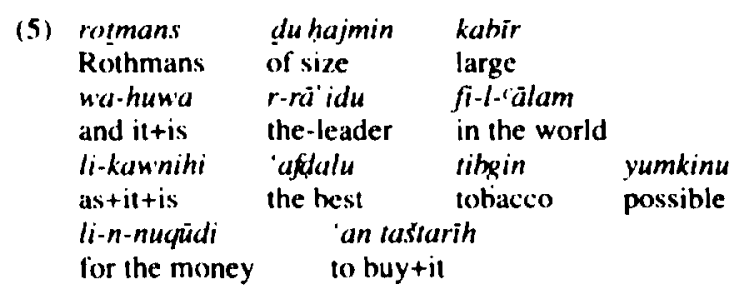

"Rothmans is of large size and it is the leader in the world as it is the best tobacco money can buy."

The structure of (4) is a combination of four clauses comprizing two complex sentences linked by means of two subordinators al-lari (which) and sawa an (whether). The same applies to (5) which consists of a complex structure.

Such long sentences, heavily loaded as they are, tend to blur the isolative emphasis intended to be assigned to each chunk of information in the advertisement. Besides, such a complex structure does nol promote the smooth processing of the message, thus alienating the mode of presentation and blurring its communicative impact. And whereas most of the Arabic advertisements analyzed above adopt a disjunctive structure, the advertisements in (4) and (5) unduly rely on subordination.

\section{Lexical Choices}

Sales advertisements employ lexical items of wide circulation in the community addressed. Homonyms, synonyms, antonyms, homophones are also frequently used. Formal, technical, and far-fetched lexical items are rarely used. A look at the students' translations shows that a good number of them have incorporated vocabulary items which occur mainly in formal discourse. Observe the formality of the vocabulary items in texts 1 to 7 (see Appendix). For example, words like al-mar (one/person), tabragih (you seek), nu-qüd 
(money), ladà (by, to), tahtä' (to buy), du martahah 'älivah (of a high rank) are rarely, if at all, encountered in sales advertisements. They naturally occur in formal and academic writing.

\section{Cohesion}

In disjunctive writing. cohesion is established by ways and means different from those used in discursive writing. Continuity of message in disjunclive writing is ensured by means of inferential, rather than referential, strategies, with the context of situation providing necessary elues. Cross referential devices are rarely resorted to: and referents are identified either by reiterating them, or by inference.

A good number of the students' translations are, however, 10o explicit when viewed in light of the above argument. and when the style in which they are written is compared with that in which the Arabic sales advertisements discussed previously. This explicitness is identified at two textual levels:

\section{a. Referential Connerctivity}

Co-referential connectives, such as hum'a (he), hiva (she), al-lati (which), etc. were so rarely (if at all) used in the Arabic sales advertisements analyzed above. It seems that undue use of such cohesive connectives goes against the intended isolative emphasis assigned to each chunk of information. In such a text-type the writer's intention seems to attract the receiver's attention to the alleged uniqueness of the elements heing advertised rather than to the relationships between the elements. Advertisement writers seem to realize this by means of appositional and disjunctive writing.

A good percentage of the translations have been unduly explicit, thus discharging the adventisements of their suspending and persuasive power. To illustrate, see example (6):

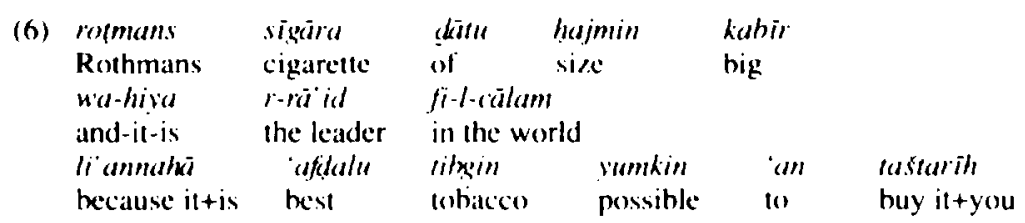

"Rothmans is a cigarette of large siec and it is the leader in the world because it is the best tobacco you can buy."

Using the conjunctives w'a (and) and li anna together with the co-referential connectives hiya (it) and -ha (it) has tumed the advertisement into an expository text of formal academic orientation. Compare the translation provided in (6) with that in (7) another student 's translation:

(7) rolmanis

Rothmans

'al-hajmur

the size

the bie

"ar-ris'idlu fi 'älami s.sakjitr.

the leader in world the cigarettes

fadalu tibigin bumkin in lastarih

best possible to buy-it-you

"Rothmans King Size The leader in the world of cigaretles. The best tobacco you can buy"

b. Logical Relationships

In this discourse genre, advertisement writers tend to impose no connectives that mark logical relationships among the components of an advertisement. They are aware 
that in most cases the content of an advertisement cannot be taken as true by the intended audience. Yet, they rely on the cooperation between the writer and the reader as regards tolerance, on the part of the reader/audience, of the exaggerated and alleged uniqueness of the commodity being advertised. Thus, they leave it up to the reader to infer the relationship intended to hold between the event and its consequences, or the commodity and its alleged attributes. To impose an explicit connective of a logical relationship on the textual components of an advertisement may lead to stripping it from its interest-generating style and turn it into an informative text. Notice how the explicitness imposed on the following text has defeated the rhetorical strategies of implicitness and disjunctiveness:

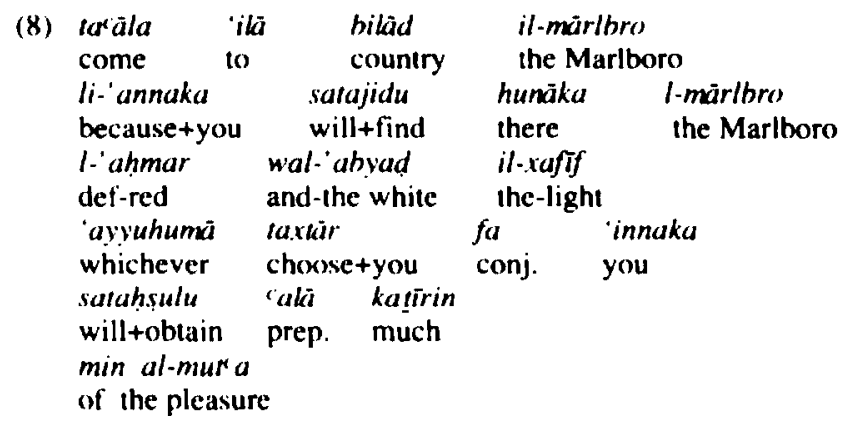

"Come to the country of Marlboro because you will find there the Red and the Light Marlboro. Whichever you choose. you'll obtain a lot of pleasure."

\section{The Relationship Between Text Typological Focus and Surface Features}

The way in which the language user chooses to communicate seems to be motivated by a number of factors, such as his purpose, the audience addressed, the relationship that holds between him and the intended audience, the relationship assumed to take place between the text and the audience, and the social function of the text. Such factors bring to bear on the way in which the message is conveyed and on the choice of lexis, syntactic structuring. and organization of content.

Advertisements, as a text type in their own right, aim to persuade and invite (Hatim and Mason 1990). The way they persuade seems to differ from that of other text types. Providing evidence, cause-effect data, examplification, and other types of logical reasoning do not seem to work well in advertising. Exaggeration, simplicity of structure, colourful style, and relying on inferencing strategies seem to be effective tools of persuading and inviting.

A look at some of the students ${ }^{*}$ translations reveals that such rhetorical features are missing. Some of the translations are closer to definitions provided in academic writings. Text (9) below illustrates this point. The text in (9) contains all the necessary components sought in an academic definition: the term/concept to be defined, the verb (often in the simple present tense), the general class of the term, and the distinguishing characteristics.

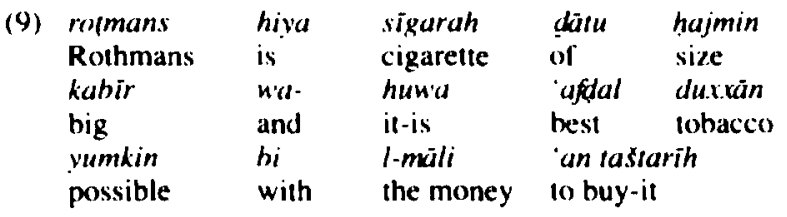

"Rothmans is a cigarette of big size and it is the best cigarette you can buy with your money." 
Passivization tends to be avoided by advertisement writers. It conventionally linkes with formal academic discourse. Recurrence of passive structures in some of the students' translations may lie behind some of the comments provided by the student evaluators. The following structures reappeared in many of the translations, yustara (is bought/can be bought), vartabaru (is considered), vumkinu sira'uhu (it is possible to buy), mu'tarafun bihi (is recognized), yusta'malu (is used/can be used), tustaxdamu (can be used), etc. Observe for instance the structure of (10):

\begin{tabular}{|c|c|c|c|c|}
\hline $\begin{array}{l}\text { (10) hiddrit } \\
\text { powder } \\
\text { custaxdamu } \\
\text { is used } \\
\text { an } \\
10\end{array}$ & $\begin{array}{l}\text { jonsum } \\
\text { Johnson } \\
\text { 'indamai } \\
\text { when } \\
\text { luriti } \\
\text { give }\end{array}$ & $\begin{array}{l}\text { li } \\
\text { for } \\
\text { furidu } \\
\text { wants } \\
\text { infihi' an } \\
\text { impression }\end{array}$ & $\begin{array}{l}\text { l'atfal } \\
\text { the children } \\
l-\text { 'um } \\
\text { the mother } \\
\text { hasisman } \\
\text { good }\end{array}$ & $\begin{array}{l}\text { li-pifliki } \\
\text { to child+her }\end{array}$ \\
\hline
\end{tabular}

"Johnson Baby Powder is used when the mother wants to give a nice impression to her child."

In addition to passivization, there are other surface features which blur the text typological focus of the advertisements. These include those features discussed previously. viz.. explicitness, recurrence of formal vocabulary items alien to the world and rhetoric of advertising. complex structure, etc.

\section{The Translation of Culture-specific Advertisements}

Text (11) proved opaque to a great number of the students (about $61 \%$ ). On analyring the translations provided and on asking the students why they translated the text in the way they did, it was found that the lexical item. swap. triggered off two opposite schemata. thus activaling interpreting strategies different from those invoked in translating the other texts. The following translations were provided of the word swap: 'allim (teach), tabic (look after), sajjil (register), 'irtani (take care of). ta'äw'an ma'a (cooperate with), "intabih li-riflik (give due attention to...).

When asked why they provided the above translations of the word sw'ap, the students explained that the meanings given in the English-Arabic (Al-Mawrid) dictionary were tolally unacceptable to them. The dictionary definition given of the word is yuckivid (to) bartering) or muckickda (barter). The students' decision not to take the dictionary definition is highly suggestive. The meanings assigned to suap in its linguistic context are clearly not inherent in it: they emanate from textual and schematic resources. The textual resources in this advertisement are three lexical items family, colucation, and child. These lexical items seem to have played a monitoring role or a frame of reference in the process of translating. They have guided the students cognitive search for a TL equivalent of the key item sw'ap.

(11) SWAP a Child this Summer Family Centre Special Education Centre

The students' first encounter with swap seems to have activated a schema - a chunk of information associated with the word - related to trade and commercial transactions: i.e. bartering a commodity for another of different nature in an economic system often associated with primitive economies. Being unaware, as it seems, of student exchange programs in western societies, the students renounced such a schema as being contradictory to and completely incompatible with another schema they have about children's status in a civilized society. Swap seems to have evoked a world far different from and opposite to that evoked by the other three lexical items child, cducation, and family. The 
meanings triggered off in this respect do not overlap on the text under consideration. This word-world relation seems to have geared and shaped the translations provided of the word swap. and. consequently, to have rendered the marked translations provided.

\section{CONCLUSION}

The study has shown that the translation of advertisements and similar culturebound texts demands that the translator (in addition to being well aware of the linguistic systems of the two languages he is dealing with) should be well versed in two types of knowledge: knowledge of registeral features relevant to the type of text he/she is translating, and knowledge of the cultural background (schematic knowledge) of the language he/she is translating from. Awareness of cultural background represents familiarity with the social, psychological, and cognitive resources verbal expression derives from. The study has also shown that awareness, on the part of the translator, of the target audience's anticipations of how a sales advertisement should unfold plays an important role in determining the Iranslator's choice of the vocabulary and syntax of the translation he/she provides. It has also been brought to the fore that the interplay among register, schematic knowledge, and awareness of the target audience's expectations constitute the main dimensions of discoursal equivalence. In translating sales advertisements, this tripartite equivalence seems to be extremely sensitive to violation.

Translator trainers are. therefore, called upon to sensitize their students' awareness of such discoursal dimensions by means of intensive training in translating different types of adverisements, and also by means of analyzing such texts in the framework of register, culture-bound expressions, and audience's anticipations.

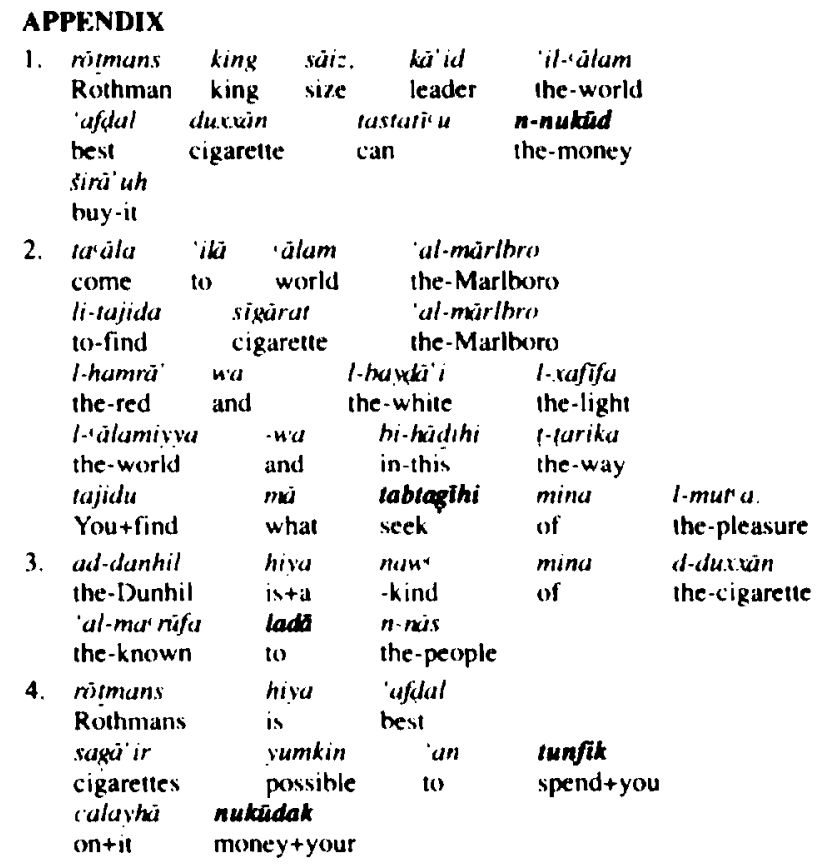




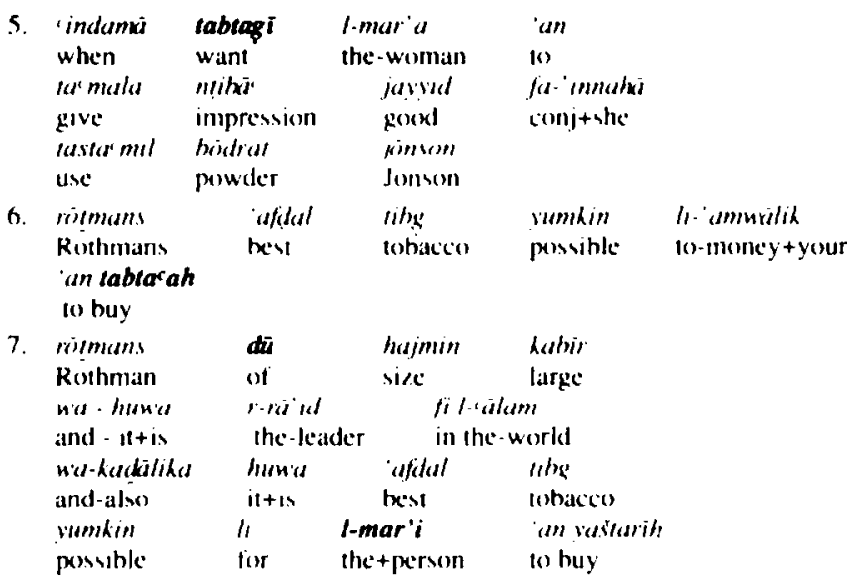

\section{REFFRENCWS}

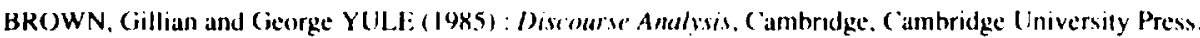

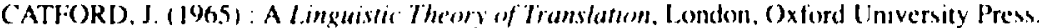

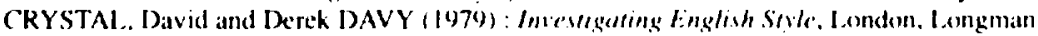

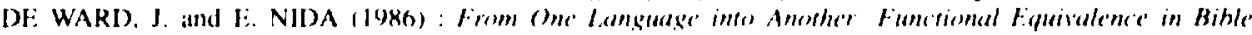
Trunskation. Thomas Nelson Publishers.

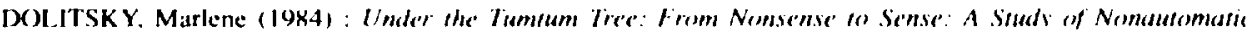
Comprehensium, Amsterdam, John Benjamins Publucation Company.

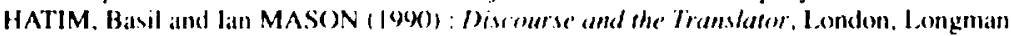

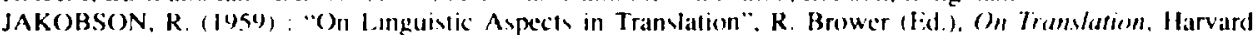
University Prews, pp. 232-2.39.

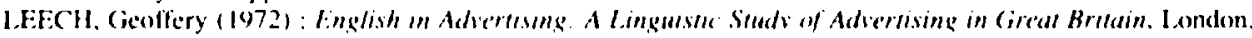
longman.

LOTFIPOUR-SAIDI. K. (19(0)): "Dixcourse Analysts and the Problem of Translation Lquivalence". Me'ta. 35. 2. pp. 289.297

NIDA. E. (19(9)): "The Role of Rheloric in Verbal Communications", Babel, 36, pp. 14.3-1.54.

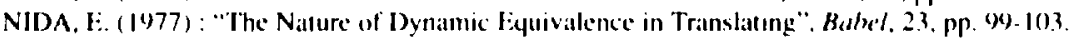

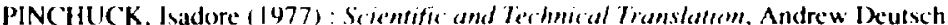

RASKIN, Victor (1986): "On Possible Applications of Script-based Stmantiss". Peter Bjarkman and Victor

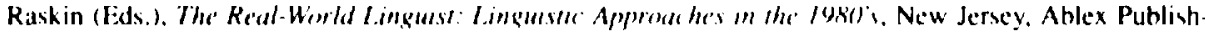
ing Corporation, pp. 19-45.

RASKIN. Victor (1985): Simanic Merhamsms of Humon, Bonton. D. Reidle Publishing (ompany. 